\title{
DISCIAIMER
}

This report was preparal as an uccount of work sponsored by an agency of the United Situles (iovernment. Neither the United Sintes (ioverninent nor any agency thereof, nor any of their employeen, maken any warranly, exprese or implied, or assumew ony legal liabllity or respunsihility l'or the necuracy, completencen, or usefulness of any information, apparalus, product, or process dincliwed, or reprenents that its use would not infringe privately owned rip.hts. Refer. ence herein to any apecific commercinl product, procens, or aervice by trade name. Irademark. manufacturer, of otherwlac doen not neceumarily conatifute or imply its endormement, recommendalion, or favoring by the Iniled Siates (ioverninent in any axency thereof. The views and opiniona of suthorn exprenued herein do not necensarily atate or reflect thuse of the Uniterl situlen (iovernment or any agency therewl. 
ISOVECTOR RESONANCES IN PION CHARGE EXCHANGE *

\section{J. DAVID BOWMAN}

Los Alamos Natione! Leboratory

Los Alamús, NM 87545

The $\left(\pi^{ \pm}, \pi^{\circ}\right)$ reactions as probes of lsovector resonances are discussed. Experimental observation of the 1sovector monopole resonance is reported. Experimental results are presented for $L=0,1$, aid 2 1sovector resonances and are compared to raniom-phase approximation calculatiolis.

Glant resonances are collective excltations of the nucleus in which large numbers of nucleons move collectively. They are simple modes of nuclear excltation that can be interpreted microscoplcally or macroscoplcally. Their experimental observation and study as well as their theoretical Interpretation are lmportant for models of nuclear excltation and the knowledge of the nucleon-nucleon interaction in the nuclear environment.

In this paper I describe a serieg of experiments that searched for and studied $L=0,1$, and 2 isovector electric resonances in the $\left(\pi^{ \pm}, \pi^{\circ}\right)$ reactions. The work was done hy a collaboration of Las Alamos Natlonal Laboratory and Tel Aviv Univeralty. A more complete account of the work is guallable elsewhere.l The experimentil properties that characterize a glant resonance are the concentration of a large fraction of the total avaliable tranation atrength with specific quantum numbers in a narrow region of excltation energy, the occurrence of resonances in wide range of nusle1, and the amooth vartation of excltation energy and width of the teaonance with nuclenr mass $A$. In contrat to the laoscalar electric modes, which have been extensively studied in the scattering of hadronic probes, the L-1, T-l or glant dipole reanance (GDH) whlch has heen studied with electromagnetic probes and the $1,-0, T-1, S-1$ Gamow-Teller reanance, whlch has been atudied in the $(p, n)$ reaction, the $l=0)$ $\mathrm{T}=1$ inovector monopole reanance (IVM) and $\mathrm{l}-2, \mathrm{~T}-1$ laovertor quadrupole resonance (IVQ) were poorly characterlzed when the preacent work was begun. The atudy of the IYM was of particular Inportance. Ita extatence had been predicted by both macroscoptc and microscoples theortea, but it had not becn obaerved. The IVM playe a central role in Coulomb effecte ouch na inospln mixing lin nuclenr ground atater, Coulomb displacement anergles and widthe of analog atnter. 
The quantum numbers and dynamical properties of the plon make the plon charge-exchange reactions $\left(\pi^{ \pm}, \pi^{\circ}\right)$ ideal for the study of electric 1sovector resonance especially the IVM. Hirst, the observation of a charge-exchange reaction which excites only 1sovector states eliminates the excltation of 1soscalar states which dominate the excitation spectra of inelastic scattering processes.

Second, at forward angles, where the angular distribution of the IVM peaks, pion charge exchange exc1tes primarily electric, or non-spin-filp transitions ( 1 n contrast to the $(p, n)$ reaction), reducing spin-filp backgrounds.

Third, the pion is a strongly aboorbed probe. The total $\pi^{+} p$ reaction cross section at the peak of the $(3 / 2,3 / 2)$ resonance $(165 \mathrm{MeV}=\mathrm{T}) 1 \mathrm{~s} 200 \mathrm{mb}$. The strong absorption of the pion is essential for the excltation of a monopole atate for which the radial integral of the transition density 18 zero. The angular distributions produced by the surface related diffractive plon scattering process (similar to ( $a, a)$ ) oscillate sharply and characteristically with angie. 4

$$
\begin{aligned}
& \frac{d \sigma}{d \Omega} \sim J_{0}^{2}(k R \theta) \text { for } L=0 \\
& \frac{d \sigma}{d \Omega} \sim J_{1}^{2}(k R \theta) \text { for } L=1 \\
& \frac{d \sigma}{d \Omega} \sim J_{0}^{2}(k R A)+3 J_{2}^{2}(k R A) \text { for } L=2
\end{aligned}
$$

where $k$ is the $\pi$ momentum, 0 a the scatering angle and $R$ ta the stronp, absorption radiua. This oaclilatory behavior serves to tdentffy the multipolartey of the transleton and to distingulah the glant resonance algnals from the nonreaunant background. In Fig. I repreaentat lve angular dlatribut lone for the ${ }^{90} \% \mathrm{r}\left(\pi^{-}, \pi^{\circ}\right)$ reaction at $165 \mathrm{MeV}$ are shown. The qualleat tue patterna of the nngular diatributione de lote depend on the detalla of the renction model uaed ao long na the plon waven are etrongly abaorbed.

lourth, he Coulomb eneryy ahift for etatea populated by the $\left(\pi^{-}, \pi^{\circ}\right)$

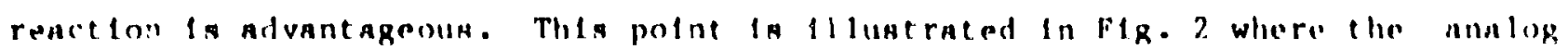
atate relationa are ahown for an 1 aovector reamance bullt on a tarket kround

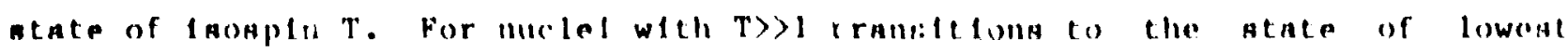

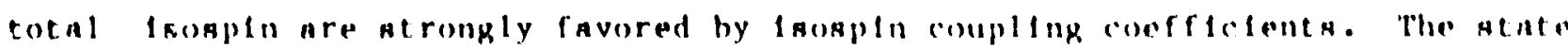

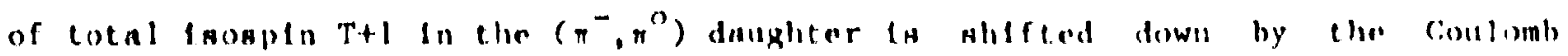




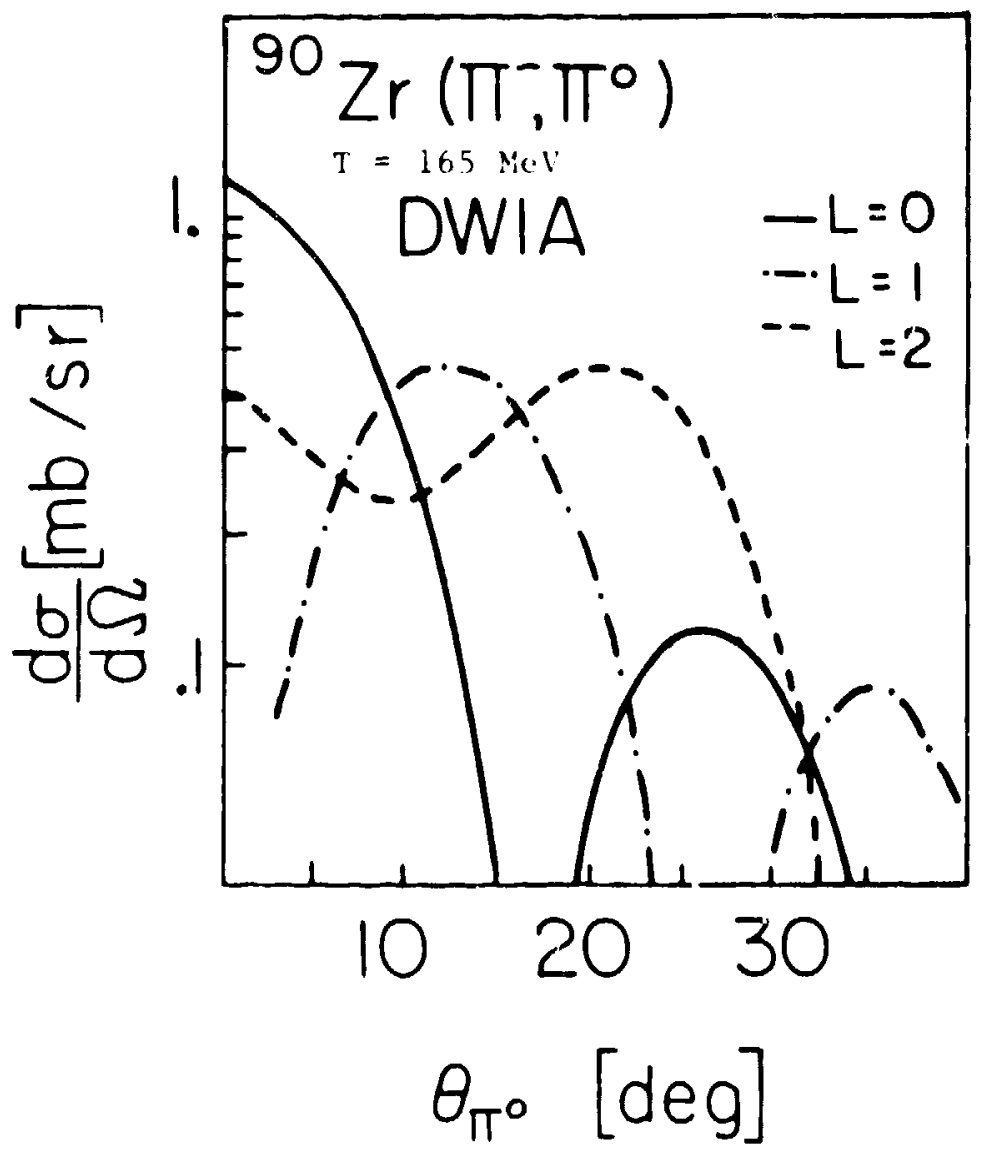

F1g. L DWIA calculations of pion charge exchange angular distribut lons at 165 $\mathrm{MeV}$ for Lm $0,1,2$ giant resonances. Tho shapes resemble the diffractive Bessel function relations. Note that the,-0 and $L-2$ angular distributlons are clearly dist ingulshable.

displacement energy relative to tta analog in the parent nucleur. Thus the $T+$ 1 atate has a relatively low excltation energy in the $\left(\pi^{-}, \pi^{\circ}\right)$ daughter and occura at an excltation energy where the denalty of atates of the same isospln 1.9 amn11. The oppostie oltuation pertalna for the $\left(\pi^{+}, \pi^{\circ}\right)$ reaction. The $T+1$ component populated in the $\left(\pi^{\circ}, \pi^{\circ}\right)$ reaction 1 a expected to be narrow and to occur at a low excltation energy whlle the $T-1$ cemponent populated in the $\left(\pi^{+}, \pi^{\prime \prime}\right)$ ranction is expected to be wide and to occur at a high excltation enerky. Of course the observation of the laosple aplitelng of reasnances ta Interesting nud is posatble if the T-1 component in not too wide.

The experlmenta deacribed here were carried out at the cilinton P. Anderson

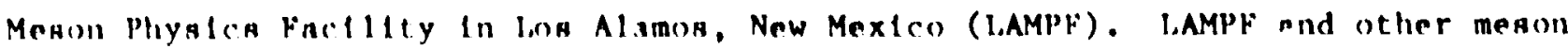
factorlas provida Intenae monochromat le charged plon beama. The nelitral piona werr detected with the laMPF $\pi^{\circ}$ epectrometer. 5 Thin npectrometer detecte

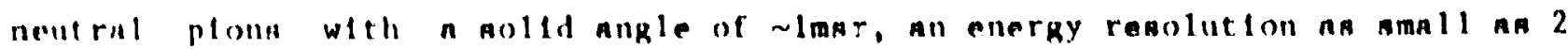




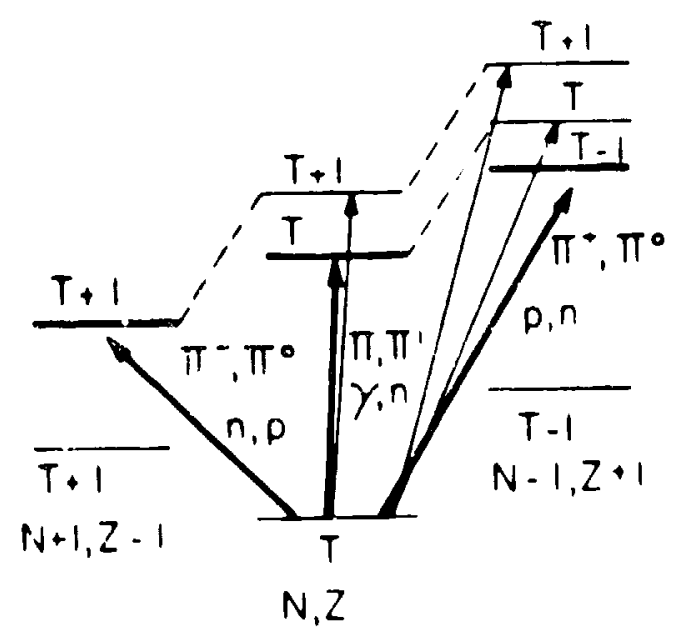

F1g. 2 Isospin allowed transitions for 1sovector resonances. The dashed linas connect states of the same isospin multiplet. For neutron rich targets the tdransitions to the lowest isospln components (thick lines) are favored. In $N=2$ nuclet $(T-0)$ transitions are allowed only to the $T+1$ multiplet. Several reactions which may be used to exclte these 1sospin components are listed.

$\mathrm{MeV}$ and an angular resolution of a few degrees. The principle of cperation of the $\pi^{\circ}$ spectrometer is as follows: Neutral plons decay nearly Instantaneously into two photons. In the $\pi^{\circ}$ center of mass frame the two photons travel in opposite directions and each has one half the $\pi^{\circ}$ rest energy. In the lab fraine the photons are thrown forward and thelr energies are no longer the same. The relationghip between the $\pi^{\circ}$ total energy $r m_{0}$ and the laboratory vartableg is

$$
\gamma m_{n}=\sqrt{(1-\cos n)\left(1-x^{2}\right)} ; \quad x=\frac{F_{1}-E_{2}}{E_{1}+E_{2}} \text {, }
$$

where $m_{0}$ is the $\pi^{\circ}$ mass, $\eta$ is the angle hetween the two protoms and ig and big. are the energles of the photons. Figure 3 shows the ${ }^{\circ}$ spectroneter ochematically. The photons are converted into $e^{+}$, e- palrs ln lend glass Cherenkov glab detectors. The ahower energy 1a absorbed in arrays of Cherenkov block detectors. The energy reaoluten of the cherenkov detectors $1930 \%$ at 100$)$ MeV. too broad for nuclenr physles work. The $\pi^{n}$ enorgy determlunt lon la based on a good menaurement of the opentng angle n uslng mult-wire proportional chambers to dotect the chargod particlea emorginp. from the alab converters. since $x$ entere Inte the expreaston for liee $n^{\circ}$ energy :n aceond order, good $\pi^{\circ}$

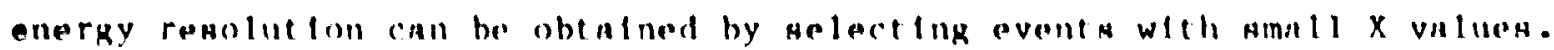




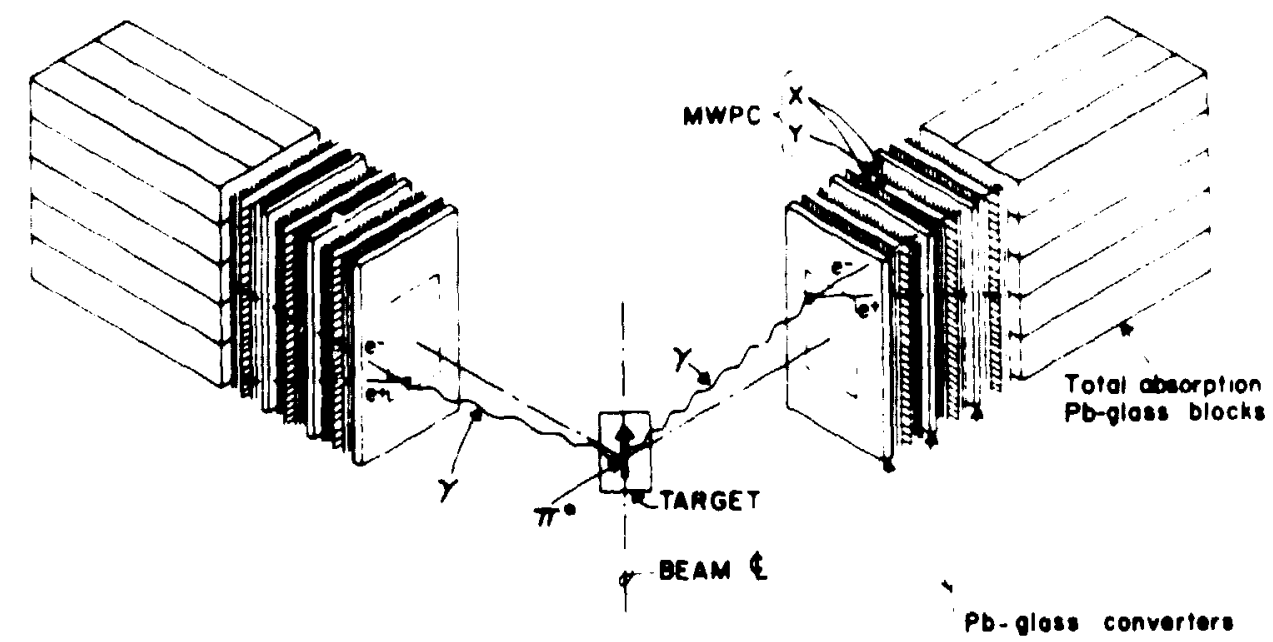

F1g. 3 Schemat1c diagram of the LAMPF $\pi^{\circ}$ spectroweter.

In the experiments ${ }^{40} \mathrm{Ca},{ }^{60} \mathrm{~N},{ }^{90} \mathrm{Zr},{ }^{120} \mathrm{Sn},{ }^{140} \mathrm{Ce}$, and ${ }^{208} \mathrm{~Pb}$, targets were bombarded with $165 \mathrm{MeV} \pi^{ \pm}$beams. Neutral plons were detected and double differential cross sections were determined for angles between 0 and $33^{\circ}$ and for $\pi^{\circ}$ energles between 90 and $180 \mathrm{MeV}$. Similar data were taken for ${ }^{40} \mathrm{Ca},{ }^{60} \mathrm{~N} 1$, and ${ }^{120} \mathrm{Sn}$ targets at $\pi$ I energles of $230 \mathrm{MeV}$. Data for the ${ }^{120} \mathrm{Sn}$ target with a $165 \mathrm{MeV} \pi^{-}$beam are shown in F1g. $4 \mathrm{a}$ and $4 \mathrm{~b}$. At the most forward angle, $4.5^{\circ}$, the IVM cross section $1 \mathrm{~s}$ expected to be the largest. The second angle, $11^{\circ}, 1 \mathrm{~s}$ chosen to be near the first minimum of the monopole angular distribution. The GDR cross section 13 small st the forward angle and has a maximura near $11^{\circ}$. Figure $4 \mathrm{c}$ shows the results of subtracting the $11^{\circ}$ spectrum from the $4.5^{\circ}$ spectrum. This subtraction suppresses the approximately isotroplc non-resonant background. The IVM algnal is the posttive-gotng hump and the small GDR glgnal Is the negat ive-going hump.

The above analysis shows the existence of peaks in the $\frac{d^{2} \sigma}{d n d E}$ versus $F$ spectra above an approximately isotropic background. The IVM peak is visible in a comparison of the $4.5^{\circ}$ and $11^{\circ}$ spectra but the GDR peak 1 s not. The subtraction procedure bakes the weak GDR peak visible. To Invegtigate the degree of laotropy of the non-reasnant background it is neceasary to look at the angular depenience of different regions of excltation energy versug scatering angle or momentum transfer $q$. In F1g. 5 I ahow the forward-angle data for $60 \mathrm{~N} 1$ $\left(\pi^{-}, \pi^{\circ}\right)$ taken at $230 \mathrm{MeV}$. Aa before, the IVM 1 a large in the most forward angle where the GDR is small. The IVM is omall at the second angle where the GDR Ia large and both are aull at the largent angle. In general crosa gectons depend on chergy loas $v$ and momentum tranafer $q^{2}$. In FtR. 6 I ahow do/dn obtalned by integrating over the three reglona indicnted in Fig. 5. Region one emphasizes 

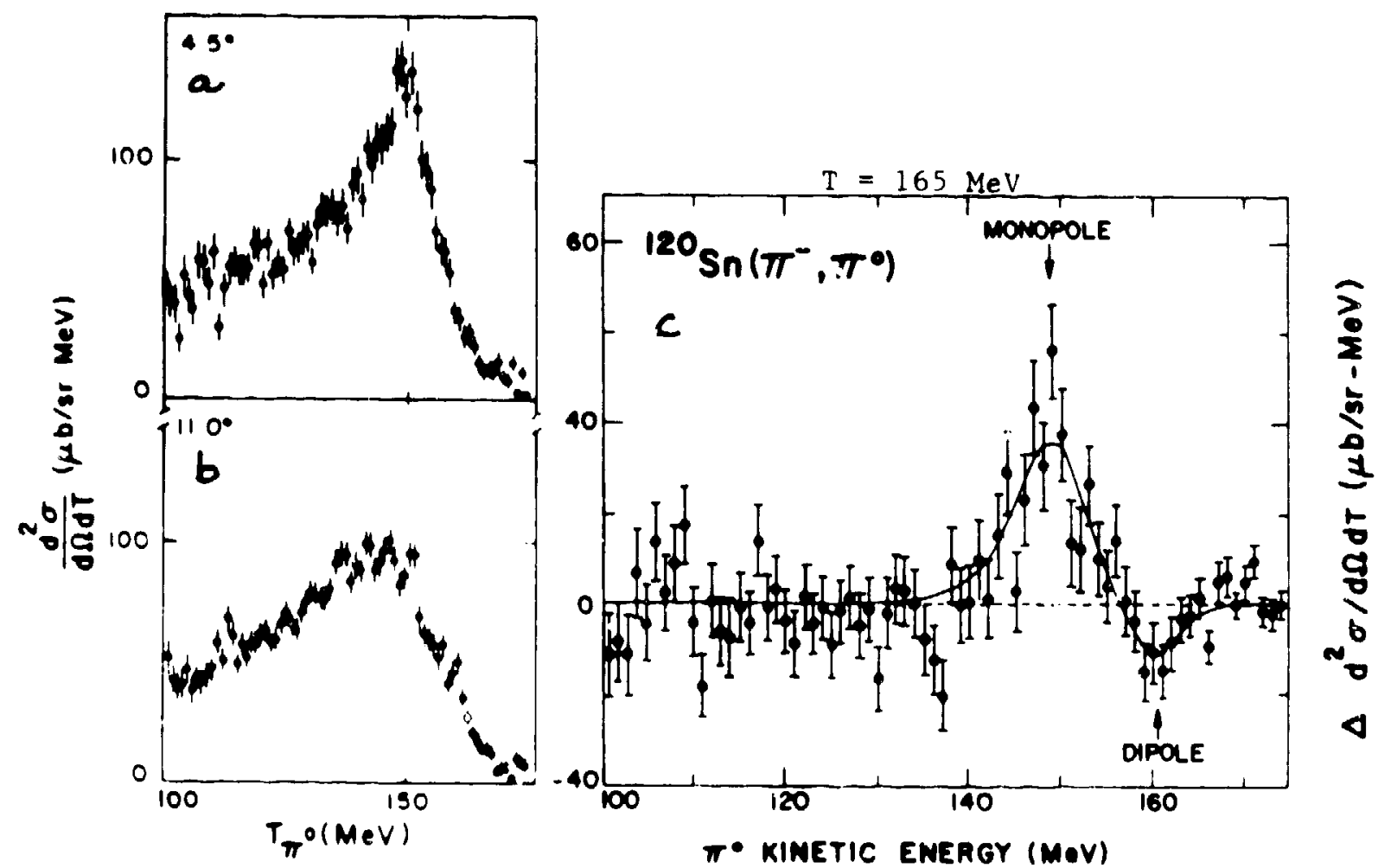

F1g. $4 a, b$ Double differentlal cross sections in the ${ }^{120} \mathrm{Sn}\left(\pi^{-}, \pi^{\circ}\right)$ reactlon at $4.5^{\circ}$ and $11^{\circ}$. Figure $4 \mathrm{C}$ is the difference of the $4.5^{\circ}$ and $11^{\circ}$ spectra.

the IVM, region two emphasizes the GDR and region thre's contilns mostly nonresonant background.

Each plot can be represented as a superposition of a background 11 near in $q^{2}$ and a component hoving the $q^{2}$ dependence expected for $d o / d \Omega$ for a $L=0$ or 1 reanance. Although the background 1 s not strictly fsotroplc its dependence on $q^{2}$ Is much less rapid than that of the glant resonances. The strongly osclllatory angular distributions of the glant resonances arise from spatial Interference of the scatered waves from the widely separated nuclear volume elements. At large excitation energles most of the observed $\pi$ yield results from knocking a nucleon out of the nucleus. At small exiltation energles the finfle energy acceptance of the $\pi^{\circ}$ spectrometer averages over many overlapplng states of different angular momentum. Both these processes result in featureless background angular distributions.

In order to quanteatively extract excltation energles, widtha, and maxtmum crose section, a least-aquares fitting procedure was followed. The double differential crose aection as a function of $q^{2}$ and $v$ was writen as a sum of two Gausalan peaks at an angle-independent excltation energy. The $q^{2}$ varlation of the penks was taken to be that of diatorted wave liapulas approximation calculation using RRA trangttion denglties. The alze of the maxtimum crosa 

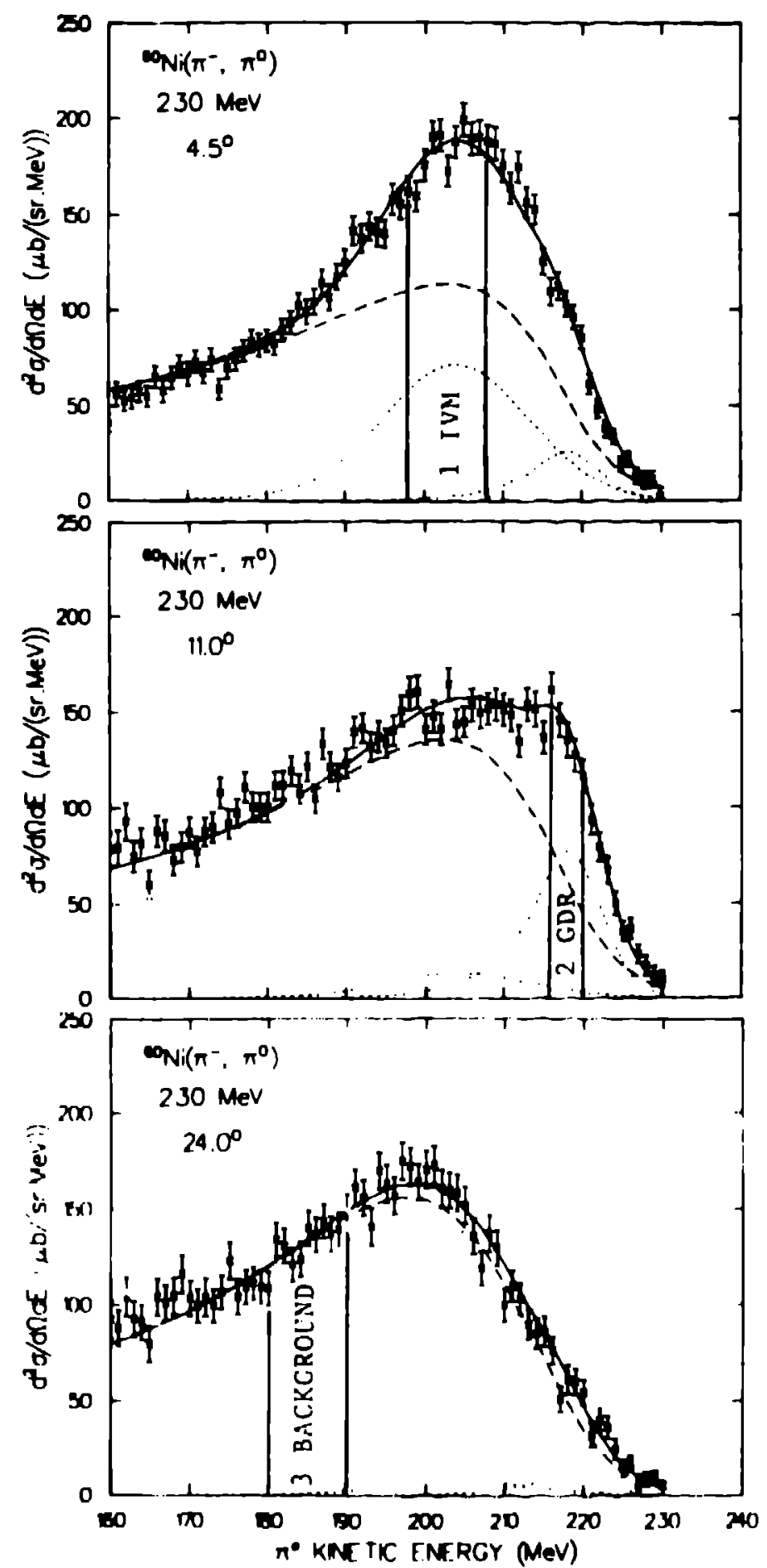

Fig. 5 Double differential cross sectione for the $60_{\mathrm{N1}}\left(\pi^{-}, \pi^{\circ}\right)$ reaction at three angles.

gectlong was varled. The background was written as a function having a smooth $v$ dependence and a quadratic $q^{2}$ dependerice. Resonance and background parametero were varled to fit the data for each target. The $A$ dependence of the background 


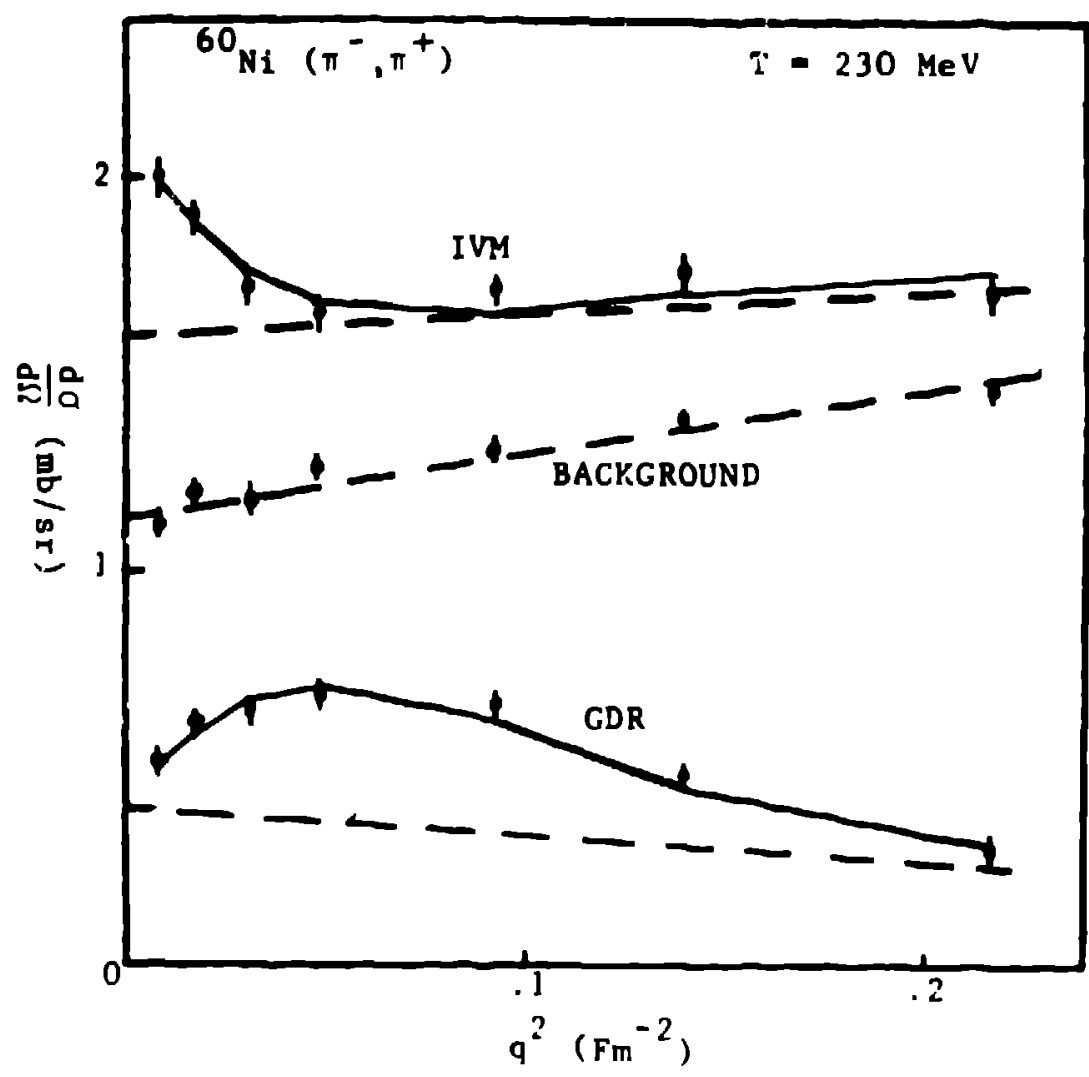

F18. 6 Differential cross sections for the three reglons defined in Fig. 5. The solid lines are $F 1 t B$ to the data. The dashed 1 ines are the components linear in $q^{2}$. The solld curves are sums of the linear components and components beling the $q^{2}$ dependence of the IVM and GDR angular distributions.

parameters was found to be a sooth function of A. Furthermore, for targets where data were taken at both 165 and $230 \mathrm{MeV}$ bombarding energy, the extracted resonance energles and widths were consigtent although the background shapeg were different. The $x^{2}$ per degree of freedom of the fits were between 1.0 and 1.3. The background function and the resonance components ohown In Fig. 5 were obtained in this way.

As a further test of the analysis procedure fits were performed as above except that the Bessel function forms for the angular distributlons were used with the etrong aborption radil treated as free parameters. The resulta for radil extracted in this way are in good agreement with values obtained from elast1c scattering as shown In F18. 7 .

In FIB. 8 and 9 I compare the extracted maximum cross aectiona, excltation energles, and widths for the IVM and GDR resonances with results of random-phase-approximation distorted-wave-1mpulae-approximat on calculationa. 


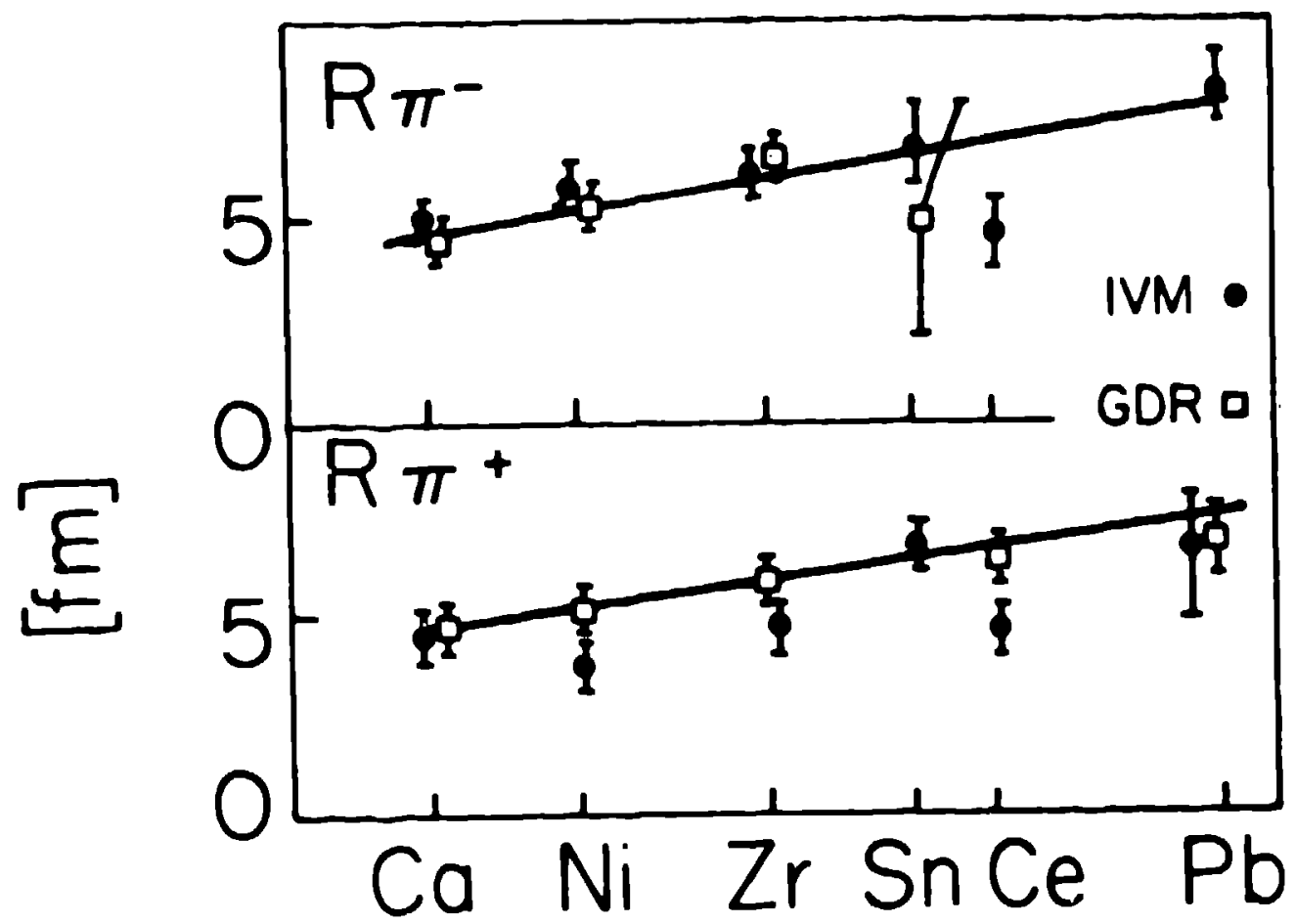

$A^{1 / 3}$

F1g. 7 Interaction radil for IVM and GDR In $\left(\pi^{ \pm}, \pi^{\circ}\right)$ reactions compared with radil from $\pi$ elastic scattering.

The A dependence of the $1 h_{\omega}$ GDR cross gections can be understood as follows. In the $\left(\pi^{-}, \pi^{\circ}\right)$ reaction a proton is turned into a neut.ron and is promoted by one mafor shel1. For the T-0 nucleus, ${ }^{40} \mathrm{Ca}$, there 18 no blocking and the $\pi^{+}$and $\pi^{-}$cross sections are comparable. For ${ }^{208} \mathrm{~Pb}$ the neutron shell $1 \mathrm{~s}$ fully occupted and the $\left(\pi^{-}, \pi^{\circ}\right)$ cross section for the GDR 19 zero. The same effect 18 seen to a lesser extent for the $A$ dependence of the 2 hw IVM maximum cross sections. Here the $\left(\pi^{-}, \pi^{\circ}\right)$ IVM cross sectlons decrease by about a factor of two from ${ }^{40} \mathrm{Ca}$ to ${ }^{208} \mathrm{~Pb}$ while the $\left(\pi^{+}, \pi^{\circ}\right)$ IVM cross sect tons are approximately cunstant. As expected, the widthe and excitation energles of $T \neq 1$ states are larger than those of the corresponding $T+1$ states. Where data are avallable from other reactions, they are also shown. The solid curves give the theoretical resclits for multipole strength welghting and the dashed curves give the regults for cross section welghting. The cross-sectlon-welghted RPA theory using the Skyrme III residual interaction qualltatively describes the data. The excltation energy and widthe for the $T-1$ component of the IVM are somewhut higher then the data, Indicating a possible influence of multi-particle-hole 
8tates. If the excitation energy of the 1 sospin $T_{<}$component of the IVM in the parent nucleus is estlmated using the RPA value of the 1sospin energy splitting the data fall on the curve

$$
E_{x} T_{<}=(59.2 \pm 2.6) A^{-1 / 6}
$$

considerably lower than the hydrodynamical estimate, 2

$$
E_{x}=170 A^{-1 / 3}
$$

So far nothing has been sald about the 1sovector quadrupole resonarice. No IVQ peak vas necessary to $f$ it the experimental double differential cross section data. A third Gaussian peak was added to the fitting function. The excitation energy, width, and $q^{2}$ dependance of the peak were taken from RPA-DWIA. The data wers refitted and $90 \%$ confidence level upper $11 \mathrm{mits}$ were deduced for the presence of an IVQ component. These upper 11mits were $0.18,0.30$, and 0.15 of the RPA-DWIA estimate of the peak IVQ cross section for ${ }^{40} \mathrm{Ca},{ }^{60} \mathrm{N1},{ }^{90} \mathrm{Zr}\left(\pi^{-}, \pi^{\circ}\right)$ respectively. For the IVM and GDR the observed cross sections were typlcally 0.60 of the RPA-DWIA calculations. Shifting the assumed excitation energles away from the RPA values did not affect the deduced upper 11mits. If a much larger width was assumed the upper $11 \mathrm{mlt}$ for the IVQ cross section was Increased and became consistant with the RPA-DWIA estimate.

Isovector quadrupole 3 trength has been observed in the $(\gamma, n)$ reaction but the extraition of the strengih is morlel dependent. Recently Wright et al.,8 have searched for the IVQ in the elast1c scattering of photons from ${ }^{40} \mathrm{Ca}$. They conclude that there $1 \mathrm{~s} 1 \mathrm{ess}$ then 0.5 of the energy-weighted sum rule estimate of IVQ strength below $50 \mathrm{MeV}$ excitation energy. Thus two different methods fali to find a compact IVQ resonance. These results pose a problem for micrcscoplc theorles of the structure of gianl resonances. Perhaps the spreading width (the mixing of multi-particle-nole components into the wave function of these resonances) which is neglected in RPA calculations is important for the IVQ.

Tsovector resonances of $L=0,1$ and 2 have been studled using the $\left(\pi^{ \pm}, \pi^{\circ}\right)$ reactions. The loovector monopole resonance was found to be a general feature of the excltation spection of nuclel from ${ }^{40} \mathrm{Ca}$ to ${ }^{208} \mathrm{pb}$. The $\mathrm{T}+1$ and $\mathrm{T}-1$ lsospin components of the laovector monopole and glant dipole resonances were observed. Random pisae approximation calculation reproduce the excltation energles and widtho of the observed IVM and GDR peaks. Randoin phase approximate, distorted wave impulse approximation calculationa approximately 


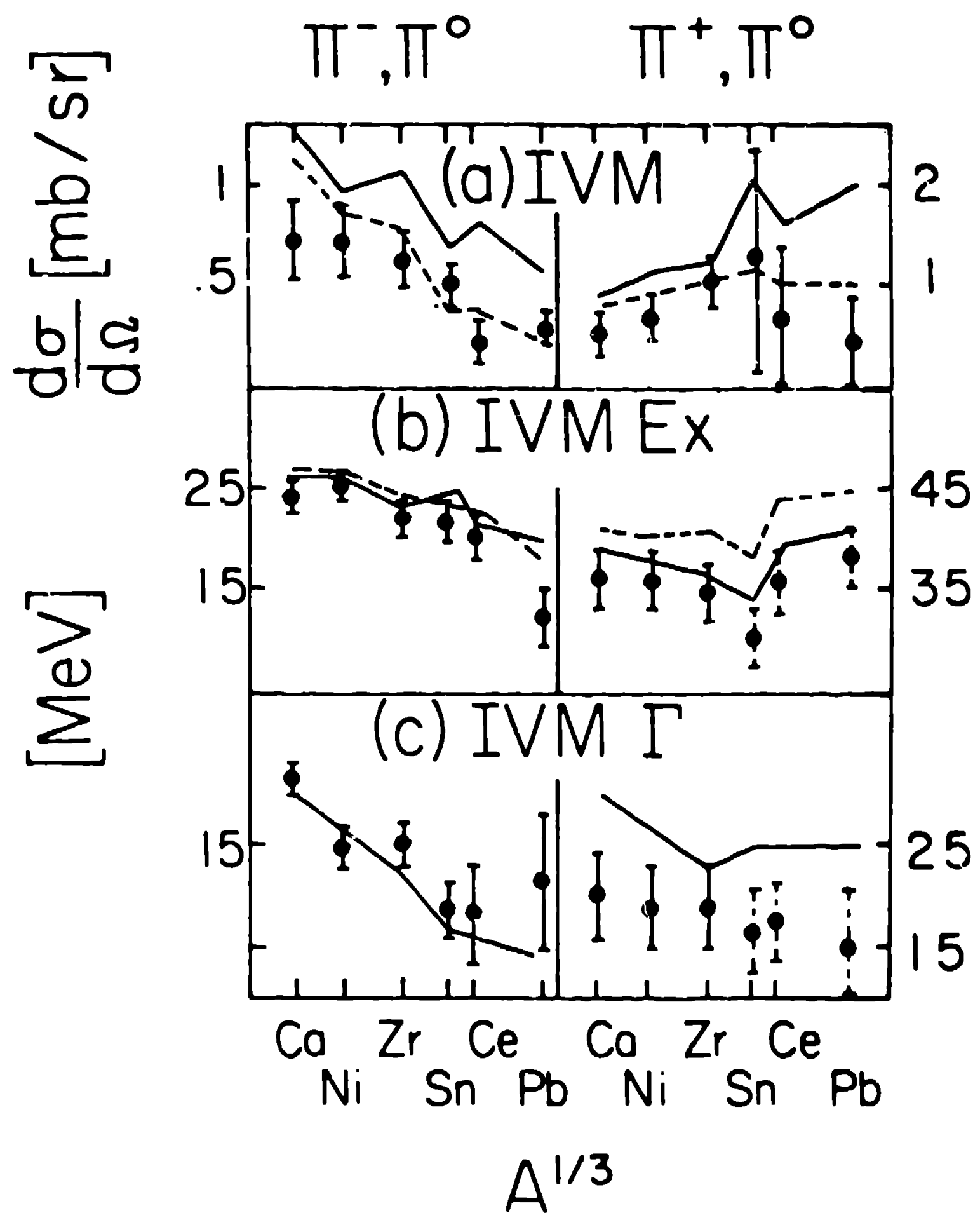

F1g. B Maxinum cross gectlons (a), excitation energles relative to the target ground state (b), and widthe (c) for the IVM.

reprciduce the observed maximum cross sectlons. No 1sovector quadrapole strengt' was ohserved inticating probleme in random phase approximate calculations of this state. 

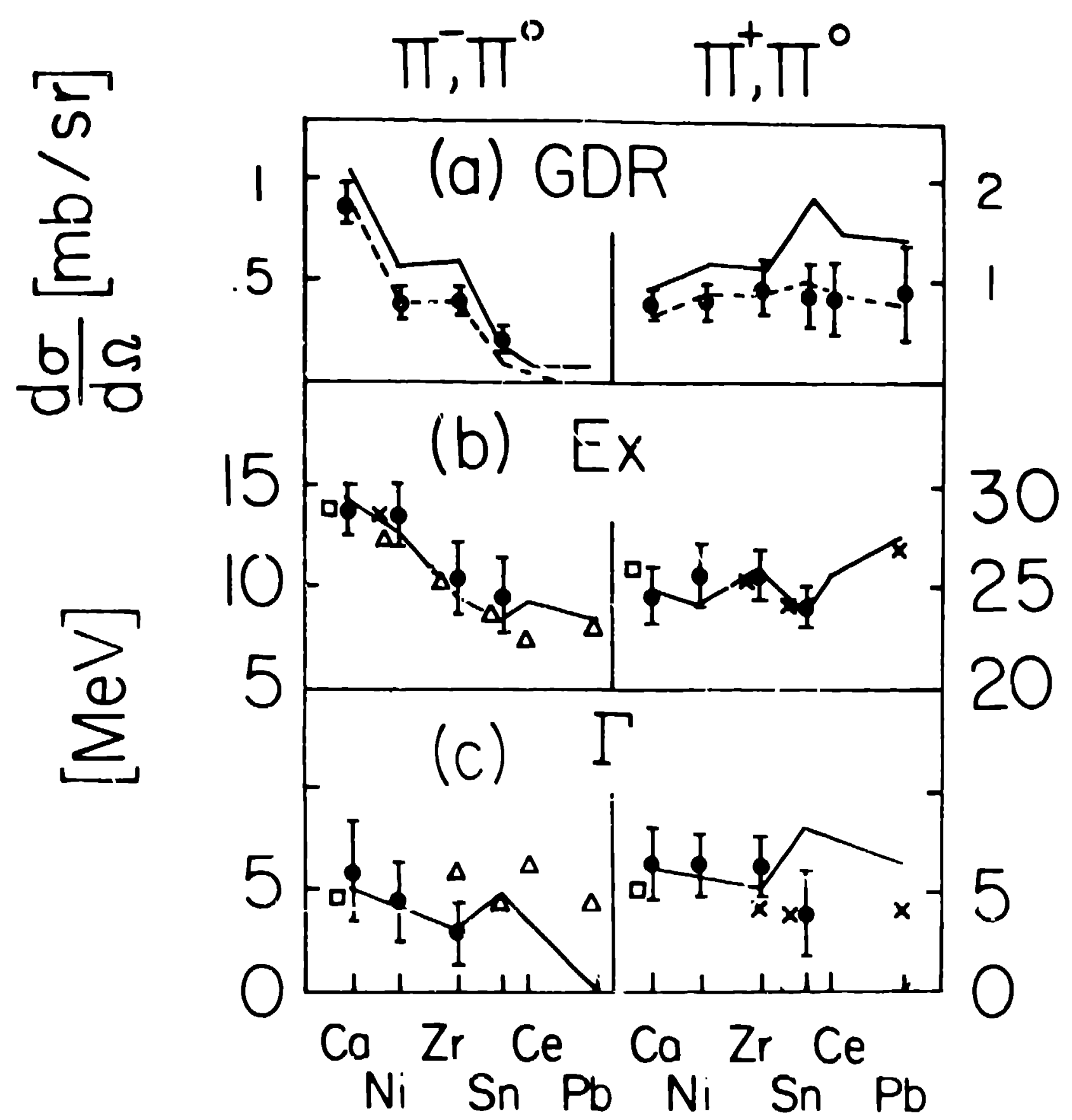

$$
A^{1 / 3}
$$

Fig. 9 Mnxtrum crose section (a), excteation energleg (b), and widthe (c) for the GIRR.

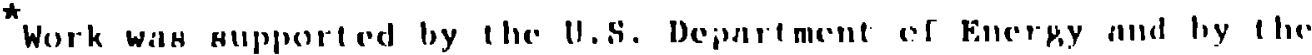

Is.-Iarael Bl nat fonal Sclence Foundat lon.
} 


\section{REFERENCES}

1. J. D. Bowman et a1., Phys. Rev. Lett. 50, 1195 (1983); A. Fre11 et al., Phys. Rev. Lett. 52, 2134 (1984); A. Ere11, FH.D. Thesis unpubl1shed, Te1 Av1v University, 1984.

2. A. Bohr and B. R. Mottelson, Nuclear Structure (BenJamin, New York, 19?5).

3. G. F. Bertach and S. F. Tsa1, Phys. Rev C18, 125 (1975); K. F. L1u and G. E. Brown, Nuc1. Phys. A265, $385(1976)$; N. Auerbach, ituc1. Phys. A182, 247 (1972).

4. J. D. Bowman et al., Phys. Rev. Lett. 46, 1614 (1981); A.Gal, Phys. Rev. C25, 2680 (1982).

5. H. W. Baer et a1., Nuc1. Inst. and Meth. 180, 445 (1981).

6. N.Auerbach and A. Kleln, Phys. Rev. C28, 2075 (1983); N. Auerbach and A. Kle1n, Nucl. Dhys. A395, 77 (1983); A. K1e1n, PH.D. Thesis, Tel Av1v Untversity, 1984 .

7. S. S. Manna et a1., Phys. Rev. Lett. 32, 114 (1974); T. W. Ph1111ns and R. G. Johnson, Phys. Rev. C20, 1689 (1979); D. M. Irake et al., Phys. Rev. Lett. 47,1581 (1981).

8. D. H. Wright et al., University of Il11no1s, Preprint 1985 (unpublished). 